\title{
New fossil non-cyclostome braconid wasps from the Lowermost Eocene amber of Paris Basin
}

Sergey A. Belokobylskij, André Nel, Alain Waller, and Gael De Plöeg

Acta Palaeontologica Polonica 55 (3), 2010: 519-527 doi: http://dx.doi.org/10.4202/app.2009.1114

Two braconid wasp taxa with enlarged eyes and ocelli indicative of probable nocturnal activity are discussed and described from the lowermost Eocene amber of the Paris Basin.The new tribe Palaeocharmontini nov., for new genus Palaeocharmon with type species Palaeocharmon basalis sp. nov. is described and illustrated in the subfamily Charmontinae. The similarity of this taxon with members of subfamilies Helconinae, Homolobinae, and Brachistinae is shown and the peculiar character [presence of hind wing recurrent vein $(\mathrm{m}-\mathrm{cu})$ ] unknown previously in non-cyclostome braconids is discussed. A third fossil species of the genus Phanerotoma (Ph. menieri sp. nov.) is described and compared with known species from the Baltic amber.

Key words: Insecta, Hymenoptera, Braconidae, parasitoids, new taxa, fossil, amber, morphological peculiarities, Eocene, France.

Sergey A. Belokobylskij [sb@zin.ru; doryctes@yahoo.com], Museum and Institute of Zoology Polish Academy of Sciences, Wilcza 64, Warszawa 00-679, Poland; André Nel [anel@mnhn.fr], Alain Waller, and Gael De Plöeg, Laboratoire d'Entomologie, Muséum National d'Histoire Naturelle, 45 rue Buffon, F-75005 Paris, France.

This is an open-access article distributed under the terms of the Creative Commons Attribution License (for details please see creativecommons.org), which permits unrestricted use, distribution, and reproduction in any medium, provided the original author and source are credited. 
